\title{
THE RELATIONSHIP BETWEEN AIRWAY RESISTANCE, AIRWAY CONDUCTANCE AND LUNG VOLUME IN SUBJECTS OF DIFFERENT AGE AND BODY SIZE ${ }^{\mathbf{1 , 2}}$
}

\author{
By WILLIAM A. BRISCOE ${ }^{3}$ and ARTHUR B. DUBOIS 4
}

\author{
(From the Department of Physiology and Pharmacology, The University of Pennsylvania \\ Graduate School of Medicine, Philadelphia, Pa.)
}

(Submitted for publication April 1, 1958; accepted April 25, 1958)

The resistance of the airways to the airflow through them depends on the radius, length and number of the airways. It has long been apparent $(1,2)$ that the bronchi are distended as well as lengthened in the inspiratory position of the lung. These two changes in the dimensions of these airways would have opposite effects on their resistance to airflow, lengthening increasing resistance and widening reducing it. More recent measurements of airway resistance have shown that it is reduced in the inspiratory position of the lung $(3,4,5)$ and is more in individuals with small lungs (6).

The body plethysmograph affords a good technique for comparing changes in airway resistance with changes in lung volume in an individual, since each measurement of airway resistance includes as an essential stage in its derivation, a measurement of intrathoracic gas volume. It therefore seemed desirable to explore further the relationship between airway resistance and lung volume at different degrees of inflation of the lung in normal subjects.

\section{METHODS}

Airway resistance was measured by the method previously described by DuBois, Botelho and Comroe (7). The method has the advantage that the pressure changes in the body plethysmograph reflect changes in alveolar pressure rather than changes in pleural or esophageal pressure. The resulting measurements are therefore assessments of pure airway resistance uncomplicated by the effects of tissue viscosity which are included with

1 This investigation was supported in part under a contract between the Army Chemical Center and the Graduate School of Medicine, University of Pennsylvania.

2 Presented in preliminary form at the Fall Meetings of the American Physiological Society, 1956.

3 Present address : Cardio-Pulmonary Laboratory (Columbia University Division), Bellevue Hospital, New York, N. Y.

4 Established Investigator of the American Heart Association. airway resistance when it is measured by means of changes in esophageal pressure.

The method previously described has been somewhat simplified by eliminating photographic recording of the oscilloscope. The oscilloscope face is now filled by a plexiglass disc on which are ruled parallel lines. While the trace is being made on the oscilloscope face the observer rotates the plexiglass disc until one of the parallel lines is aligned with the tracing. ${ }^{5}$ The slope of the lines on the disc is read off scales on the oscilloscope face housing. These scales are in terms of 1 . lung volume $X$ airway resistance, and 2 . lung volume. The former scale applies when the subject is breathing freely through the flowmeter and the ordinates and abscissae on the oscilloscope face are, respectively, plethysmograph pressure and airflow. The latter applies when the subject is panting against a closed shutter and the ordinates and abscissae are, respectively, plethysmograph pressure and mouth or alveolar pressure (Figure 1 ).

Each subject sat in the 600 liter body plethysmograph for a few minutes until the air in the box was warm enough and sufficiently saturated with water vapor for spontaneous changes in plethysmograph pressure over a period of 10 seconds to be negligible. During this time the amplification of the record of plethysmograph pressure was adjusted until a displacement of $30 \mathrm{cc}$. to or from the plethysmograph gave a deflection of two inches on the oscilloscope face. The subject then put his mouth over the flowmeter shutter assembly which was suspended in the plethysmograph and panted for about six seconds. The observer aligned the plexiglass disc with the midslope of the tracing and read the product (lung volume $\times$ airway resistance) off the calibrated scale. The observer then operated a switch, which closed the solenoid shutter at the mouth, and replaced the record of flow rate by one of mouth pressure, on the $\mathrm{Y}$ axis of the

5 A more detailed description of this modification is being prepared. Meanwhile, the diagram (Figure 1) shows the arrangement of apparatus used in the present study. The oscilloscope tracing was sometimes alinear, showing a tendency to curve at its extremities, due presumably to turbulent flow at higher flow rates. The slope which was measured was that of the central part of the tracing, where flow was small (less than 0.5 liters per second), and apparently-from the linearity of the tracing -streamlined. It is for this reason that it is justifiable to use Equation 4 in the discussion (a modification of Poiseuille's equation for laminar flow) in assessing the relative distensibility of the airways and of the lung. 


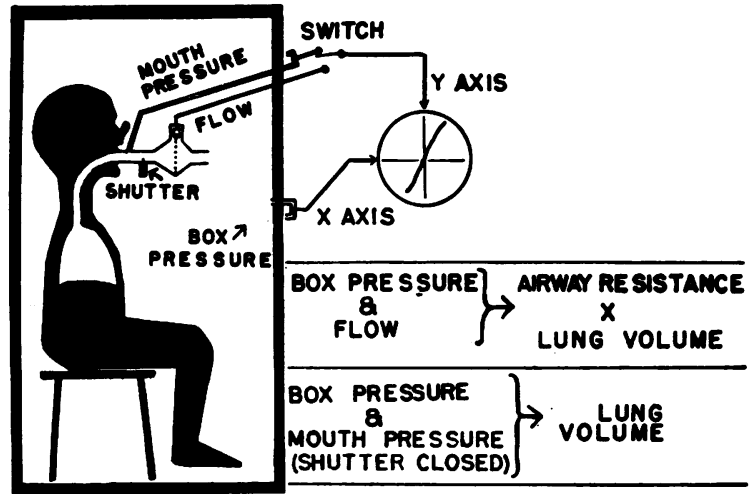

Fig. 1. Body Plethysmograph As Used in Present Study, Showing the Sites at Which Mouth Pressure, BoX Pressure and Flow are Measured

The two pairs of measurements shown at the right give the numerator and denominator of airway resistance. The switch which connects the $Y$ axis of the oscilloscope to mouth pressure also closes the shutter. The three amplifiers used are omitted.

oscilloscope face. The subject continued his panting efforts against the shutter for about two seconds and then withdrew the mouthpiece from his mouth. In the meantime the observer aligned the plexiglass disc with the fluorescent trace of mouth pressure versus box pressure and read lung volume off the scale.

This procedure was repeated up to 45 times during any one session of a subject inside the plethysmograph. During some observations subjects were instructed to hold their chests in an expiratory position, close to their residual volume. In other cases each subject was instructed to hold his chest in an inspiratory position. In this way measurements of airway resistance were made over a wide range of lung volumes in most subjects. The rapid switch from flow to mouth pressure made it possible to measure the volume of the lung at which the panting was performed and eliminated the chance of a change

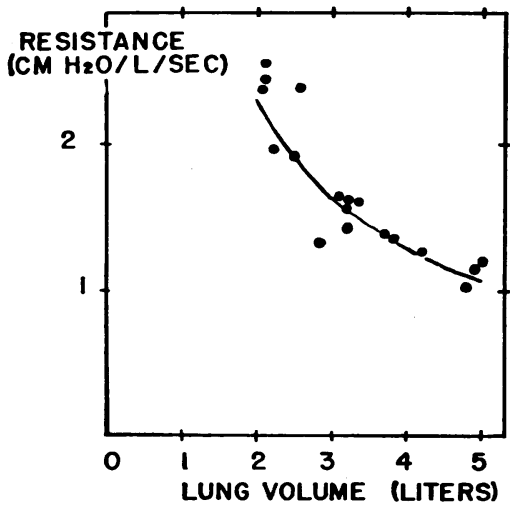

Fig. 2. Airway Resistance Plotted Against Lung Volume in Subject J.Z. in the volume between the measurements. Some subjects were studied on more than one occasion.

In the calculation of airway resistance an allowance of $0.78 \mathrm{~cm} . \mathrm{H}_{2} \mathrm{O}$ per liter per second was made for the measured resistance of the pneumotachygraph used. For reasons explained later airway resistance was expressed in terms of its reciprocal, airway conductance, in units of liters of airflow per second per $\mathrm{cm}$. of water pressure.

It seemed desirable to check on the accuracy of the volume measurements made by the plethysmograph. A bottle was substituted for human lungs. The pressure in the bottle was measured by the mouth pressure manometer. The gas in the bottle was compressed by means of a rubber bulb connected to it, and squeezed by the hand of an operator, sealed in the plethysmograph with the bottle, and holding his breath during observations. The volume of the bottle was measured by the slope of the oscilloscope tracing of plethysmograph pressure against "mouth pressure" by a second operator outside the box, exactly as for human lungs. The bottle contained 0.1 liter of Dreft detergent solution and 4.0 liters of air. Its volume was underestimated at 3.4 liters by the plethysmograph procedure. But when the Dreft ${ }^{\circledR}$ was partly converted into a fine froth, with bubbles about $1 \mathrm{~mm}$. diameter, and filling the bottle, the gas volume was correctly estimated at 4.0 liters. Evidently the gas in the bottle behaves adiabatically when there is no froth. When intimately mingled with froth the air behaves isothermally during compression, and volumes are correctly estimated by our procedure. The human lung, in its heat exchanging properties, must resemble the froth filled bottle rather than the froth free bottle, and our plethysmograph procedure estimated correctly the volume of the air spaces which exchange heat rapidly with their walls.

\section{RESULTS}

All subjects reported here were normal. They were laboratory workers, or the relations of laboratory workers, except for a circus dwarf. One hundred twenty-nine measurements of airway conductance and alveolar volume were made on 8 children studied on 9 occasions, aged between 4

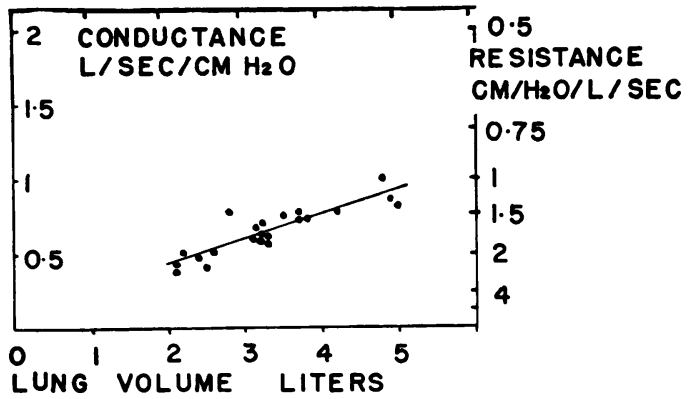

Fig. 3. Airway Conductance Plotted Against Lung Volume in Subject J.Z. 
and 13 years; 129 measurements were made on 7 women studied on 9 occasions and aged between 16 and $87 ; 327$ measurements were made on 11 men, including one circus dwarf (B), studied on 18 occasions and aged between 23 and 40 .

The data for each subject were plotted on a scatter diagram. When airway resistance was plotted against lung volume there was a curvilinear relationship between them (Figure 2). However, when airway conductance was plotted against lung volume there appeared to be a linear relationship. ${ }^{6}$ It was decided therefore to relate airway conductance (6) rather than airway resistance to the various lung volumes at which measurements were made in each subject (Figure 3 ).

The results are given in Table $\mathrm{I}$, which gives the age and physical characteristics of each subject together with the number of observations made at each session on each subject, the mean lung volume, the mean conductance, the regression of conductance on lung volume, the intercept of the regression line on lung volume at zero conductance and the correlation coefficient, at each session on each subject.

The regression lines are plotted in Figures 4, 5 and 6 , which express the data on children, women and men, respectively. Each line extends between the maximum and minimum lung volumes at which measurements of airway conductance were made at any particular session on a subject. All lines reflect the same tendency for airway con-

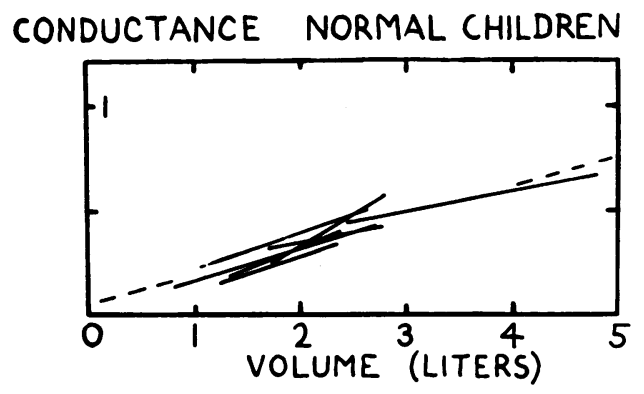

Fig. 4. Regression Lines of Airway Conductance on Lung Volume in ChILdRen

The dashed line is the regression line for all data on children.

${ }^{6}$ This does not rule out the possibility of curves hidden within the group of points which scatter about the regression line describing the best fit to the general trend. The mid-slope $\Delta \mathrm{C} / \Delta \mathrm{V}$ sometimes appears less steep than the extremes.

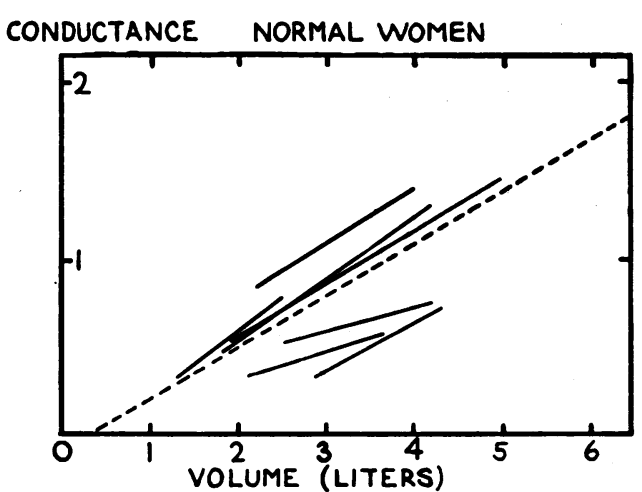

Fig. 5. Regression Lines of Airway Conductance on Lung Volume in Normal Women

The dashed line is the regression line for all data on women.

ductance to increase as lung volume increases. It is seen that children show the decreased airway conductance which is compatible with their smaller lung volume. The airway resistance of children is three to five times as much as that of adults.

Age appears to have little effect on the relationship between airway conductance and lung volume. In Figure 7 the data on five subjects with ages ranging from 4 to 87 are plotted. They all lie close to the same line which expresses the approximate relationship: Conductance $=1 / 5$ lung volume. In children the overall regression of conductance on volume was conductance $=0.14$ (volume +0.49 liter), with a correlation coefficient of 0.83 . In women it was conductance $=0.29$ (volume -0.27 liter), with a correlation cofficient

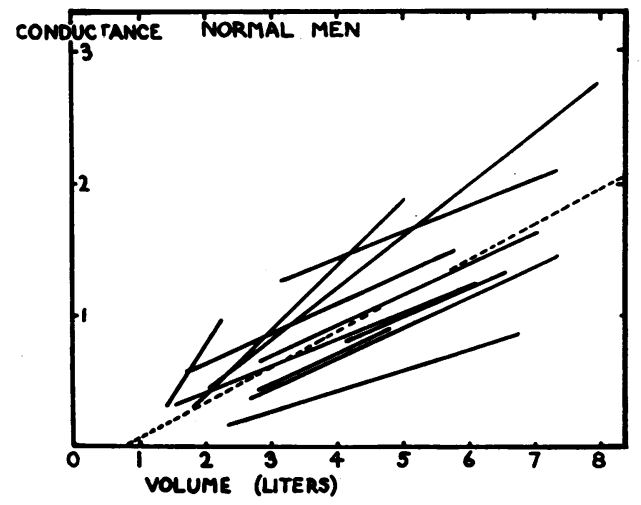

Fig. 6. Regression Lines of Airway Conductance on Lung Volume in Normal Men

The dashed line is the regression line for all data on men. 
TABLE I

Relationship between airway conductance $(C)$ and lung volume $(V)$ in 26 individuals of different physical characteristics studied at different lung volumes in each individual, some of whom were studied on repeated occasions*

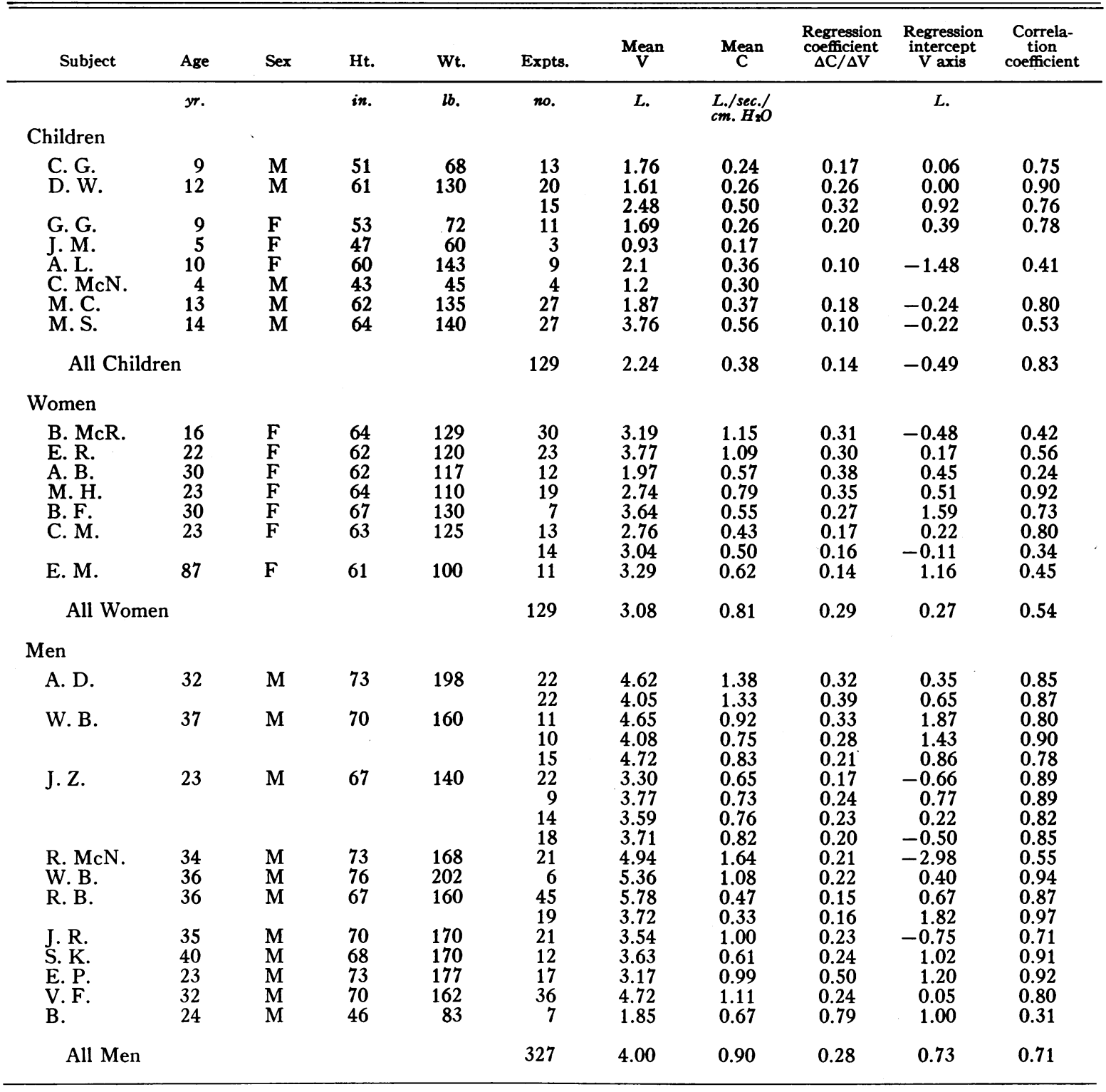

* Grouped according to children, women and men.

of 0.54 . In men it was conductance $=0.28$ (volume -0.73 liter $)$, with a correlation coefficient of 0.71. In individuals the correlation coefficients were higher than they are in this grouped data (Table I).

\section{DISCUSSION}

The results show that airway conductance increases when lung volume is increased by inspira- tion of air in an individual. When children are compared to adults, the larger individuals with larger lungs have higher airway conductance.

In men and women the regression line of airway conductance against lung volume intercepts the volume scale at a positive value at zero conductance. Insofar as it is justifiable to extrapolate a regression line this implies that airway resistance 


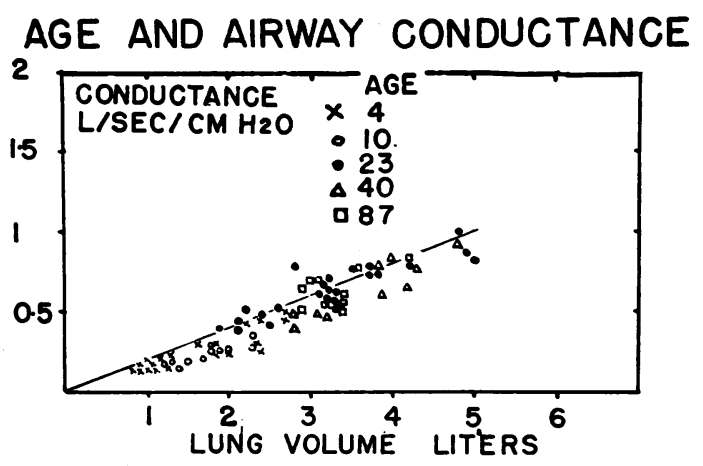

Fig. 7. The Relationship Between Age and Airway Conductance (Left) and Airway Resistance (Right) in Five Subjects Each Studied at Various Lung Volumes

The major determinant of airway resistance is lung volume and age has little effect. The line expresses the approximate relationship conductance $=1 / 5$ lung volume.

will become infinite before the lungs have completely emptied. This accords with the fact that lungs do not collapse completely on the autopsy table. The intercept in children, however, is negative although their lungs like those of adults do not collapse completely when the chest is opened. It seems therefore that these regression lines only apply over the range of lung volumes in which the observations were made. These ranges are indicated for each case in Figures 4, 5 and 6.

Airway conductance may increase as much as fourfold when an individual inflates his lungs from residual volume up to total lung capacity. This is somewhat greater than the estimate of 2.5 times by Mead and Whittenberger (4). Since the effect of lung volume on airway conductance and resistance is so marked, studies of changes in airway resistance after experimental or therapeutic procedures in individuals may be invalidated if concomitant changes in lung volume are not taken into account. Several methods of correction could be used but it seems best to use the slope of the regression line of conductance on lung volume in all adults studied. A sample calculation of this is given in the following paragraph.

In Figure 11 in the paper of Fry, Ebert, Stead and Brown (5), the mean value of $\Delta$ conductance/ $\Delta$ alveolar volume in their three normal subjects can be calculated to be about 0.35 . In our sub-

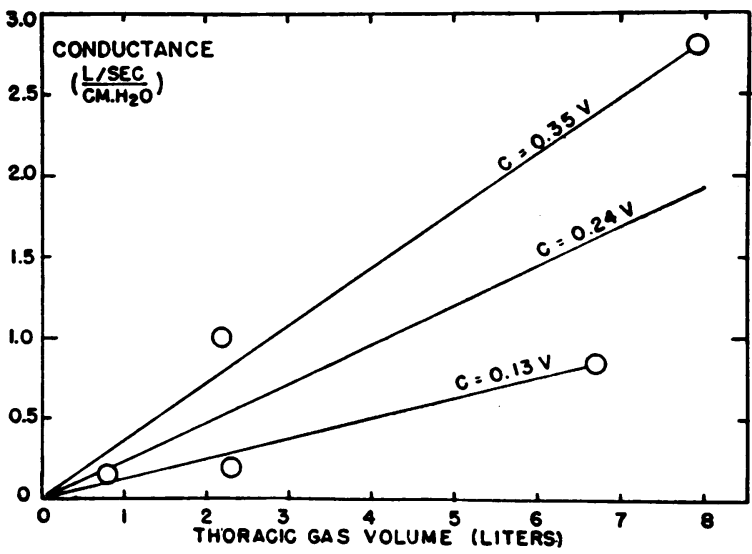

Fig. 8. Points Which Include the Outermost Values of Regression Lines in Figures 4, 5 and 6, and the Lines Which Are Estimated to Allow Approximate Prediction, From Thoracic Gas Volume, of THE UpPer Limit, Mean, and Lower Limit of AIRWay Conductance in Most Normal Men, Women and CHILDREN

jects this mean regression coefficient is 0.28 . If conductance were initially 1.0 (resistance 1.0 ) and if as a result of a therapeutic procedure lung volume increased by $500 \mathrm{cc}$. then conductance would be expected to have increased by 0.14 and airway resistance would be expected to have fallen to 0.88 . This change would have occurred in association with the change in lung volume and without the necessity of invoking any therapeutic effect of a bronchodilator.

It seems possible to use our data in tentative consideration of the order of magnitude of the relative distensibility of the lung as a whole in comparison to that of the resistance airways, i.e., those airways which have the major part of the airway resistance of the whole lung. Consider a small spherical group of alveoli supplied by one resistance airway leading from the periphery to the center of this sphere.

Let $\mathrm{V}=$ lung volume in $\mathrm{cc}$. and $\mathrm{R}=$ radius in $\mathrm{cm}$. of the spherical mass of lung. Let $1=$ length in $\mathrm{cm}$. of the resistance airway in this sphere. $\mathrm{C}=$ conductance in $\mathrm{cc}$. per $\mathrm{cm} . \mathrm{H}_{2} \mathrm{O} \cdot$ second, and $\mathrm{C}^{\prime}=$ conductance in $\mathrm{cm} .{ }^{5}$ per dynes second. Let $r=$ radius of airway in $\mathrm{cm} ., \eta=$ viscosity of air in dynes second per $\mathrm{cm} .{ }^{2}$ and $\mathrm{b}=$ the regression of $\mathrm{C}$ on $\mathrm{V}$. In the simplest case where the re- 
gression line of $\mathrm{C}$ on $\mathrm{V}$ intercepts the $\mathrm{V}$ axis at zero $^{7}$ :

$\mathrm{C}^{\prime}=\frac{\mathrm{bV}}{981}$ from the regression line of $\mathrm{C}$ on $\mathrm{V}, \quad 1$ $\mathrm{V}=\frac{4}{3} \pi \mathrm{R}^{3}$ from the equation for a sphere, $\quad 2$

$\mathrm{C}^{\prime}=\frac{4 \pi \mathrm{R}^{3} \mathrm{~b}}{3 \times 981}$ from 1 and 2,

$\mathrm{C}^{\prime}=\frac{\mathrm{r}^{4} \pi}{81 \eta}$ from Poiseuille's equation. ${ }^{5}$

Let us assume that as the lung expands the airways lengthen in proportion to other linear dimensions related by a constant $\mathrm{k}$ :

$$
\begin{aligned}
& 1=\mathrm{kR}, \\
& \mathrm{C}^{\prime}=\frac{\mathrm{r}^{4} \pi}{8 \eta \mathrm{k} \mathrm{R}} \text { from } 4 \text { and } 5, \\
& \frac{\mathrm{r}^{4} \pi}{8 \eta \mathrm{kR}}=\frac{4 \pi \mathrm{R}^{3} \mathrm{~b}}{3 \times 981} \text { by equating } 3 \text { and } 6, \\
& \frac{\mathrm{r}^{4}}{\mathrm{R}^{4}}=\frac{4 \times 8 \times \mathrm{bk} \eta}{3 \times 981} \text { by rearranging and } \\
& \text { cancelling, }
\end{aligned}
$$

whence

$$
\frac{\mathrm{r}}{\mathrm{R}}=\sqrt[4]{\frac{4 \times 8 \times \mathrm{bk} \eta}{3 \times 981}}
$$

Since all the terms on the right are constant, the ratio $r / R$ is also constant, in which case the radius of the resistance airways increases by the same fraction as the radius of a sphere of lung during inflation, i.e., the resistance airways are as distensible as the alveoli. ${ }^{8}$ This is in general agreement with the findings of Shepard, Campbell, Martin and Enns (8) on the changes in the dead space with lung volume as determined by single breath analysis.

\footnotetext{
${ }^{7}$ In the more complicated case where this is not so and where the regression line at zero conductance intercepts the $\mathrm{X}$ axis at a volume of several hundred cc., as in some of our subjects, the error in the considerations of $\mathrm{dr} / \mathrm{dR}$ which follow is about 20 per cent. This is negligible when, as here, we are considering orders of magnitude.

${ }^{8}$ For purposes of this discussion, "distensibility" is defined as the fractional change of radius resulting from a given change in transpulmonary pressure (i.e., mouth pressure minus intrapleural pressure). Expansion of the lung puts tension on the lung tissues, which presumably by traction lengthen and widen the air passages. Unfortunately, we do not know the magnitude and direction of these tension forces in the lung tissues.
}

Substituting known values, $\mathrm{b}=0.28, \eta=1.98$ $\times 10^{-4}$, into Equation 9, we find

$$
\frac{\mathrm{r}}{\mathrm{R}}=0.03 \times \sqrt[4]{\mathrm{k}}
$$

In a group of alveoli supplied by one resistance airway leading from the periphery to the center of the group, $\mathrm{k}$, and its 4th root, cannot be very different from unity. If our observed regression of $\mathrm{C}$ on $\mathrm{V}$ applied to such a group of alveoli, it would suggest that the radius of the resistance airway is about 3 per cent of the radius of the alveolar mass. In a lung composed of many such groups of alveoli arranged in parallel, our data would have the same meaning since parallel conductances and lung volumes can be added. Since the major part of the resistance is in the smaller airways (9) and since the relationship in Equation 10 is dependent not on $\mathrm{k}$ itself but on its relatively unchanging 4th root, it may be that this concept of small groups of alveoli each supplied by one resistance airway can in fact be applied to the whole lung.

\section{Simplified formulas for predicting airway conduct- ance and resistance}

In deciding whether the airway resistance measured on a patient lies within normal limits, it is desirable to have a formula for predicting the mean and range of values for resistance which one may encounter on normal subjects. Such a formula should not include very unusual data, nor should it be more complicated than the known principles warrant. Unfortunately, statistics do not take some of these considerations into account. However, we may, by inspection, hope to derive some simple equations to include about 95 per cent of normal cases.

All regression lines of airway conductance on lung volume lay within an area on the volumeconductance graph bounded by the points $(0.8$, $0.15),(2.3,0.20),(6.7,0.85),(7.9,2.8)$ and $(2.2,1.0)$. The range of normal is more simply delineated by an angle formed by points $(7.9,2.8)$, $(0,0)$ and $(6.7,0.85)$. This excludes the point $(2.2,1.0)$ obtained on a dwarf in full inspiration, and the point $(2.3,0.2)$ obtained on one subject, R. B., in full expiration, yet includes all the remaining data on men, women and children (it 
even includes data on the dwarf and on Subject R. B. at ordinary breathing levels). These lines have the equations: $\mathrm{C}=0.13 \mathrm{~V}$ and $\mathrm{C}=0.35 \mathrm{~V}$.

The mean predicted conductance for men and women can be obtained from the regression lines stated in the text, or can be simplified by inspection to: $\mathrm{C}=0.24 \mathrm{~V}$ (range, $0.13 \mathrm{~V}$ to $0.35 \mathrm{~V}$ or \pm 46 per cent). These points and lines are shown in Figure 8. The predicted airway resistance would then be: $\mathrm{RA}=4.2 / \mathrm{V}$ (range, $2.9 / \mathrm{V}$ to $7.7 / \mathrm{V})$. The borderline between normal and slightly abnormal is not at present sharply defined, and these equations should be applied with caution in questionable cases until further experience has been obtained.

\section{CONCLUSIONS}

Five hundred forty-six measurements of airway resistance and lung volume were made on 26 normal subjects of both sexes, with ages ranging from 4 to 87 years. In each subject studies were made at different degrees of inflation of the lung. Airway conductance, the reciprocal of resistance, was approximately linearly related to the degree of inflation of the lungs. Regressions of airway conductance on lung volume are given for children, women and men. Airway resistance in children is three to five times that of adults. This is related more to differences in lung volume than to differences in age. A method is suggested for correcting changes in airway resistance for concomitant changes in lung volume during studies on airway resistance. Theoretical considerations suggest that the small airways in which resistance to flow is located may be as distensible as the lung as a whole. A simplified method for predicting normal limits for airway conductance at different lung volumes is given.

\section{REFERENCES}

1. Heinbecker, P. A method for the demonstration of calibre changes in the bronchi in normal respiration. J. clin. Invest. 1927, 4, 459.

2. Macklin, C. C. The musculature of the bronchi and lungs. Physiol. Rev. 1929, 9, 1.

3. Dayman, $H$. Mechanics of airflow in health and in emphysema. J. clin. Invest. 1951, 30, 1175.

4. Mead, J., and Whittenberger, J. L. Physical properties of human lungs measured during spontaneous respiration. J. appl. Physiol. 1953, 5, 779.

5. Fry, D. L., Ebert, R. V., Stead, W. W., and Brown, C. C. Mechanics of pulmonary ventilation in normal subjects and in patients with emphysema. Amer. J. Med. 1954, 16, 80.

6. Marshall, R. The physical properties of the lungs in relation to the subdivisions of lung volume. Clin. Sci. 1957, 16, 507.

7. DuBois, A. B., Botelho, S. Y., and Comroe, J. H., Jr. A new method for measuring airway resistance in man using a body plethysmograph: Values in normal subjects and in patients with respiratory disease. J. clin. Invest. 1956, 35, 327.

8. Shepard, R. H., Campbell, E. J. M., Martin, H. B., and Enns, T. Factors affecting the pulmonary dead space as determined by single breath analysis. J. appl. Physiol. 1957, 11, 241.

9. Rohrer, F. Der Strömungswiderstand in der menschlichen Atemwegen und der Einfluss der unregelmässigen Verzweigung des Bronchialsystems auf den Atmungsverlauf in Verschiedenen Lungenbezirken. Pflüg. Arch. ges. Physiol. 1915, 162, 225. 